\title{
Coletivos e o ciclo de protestos dos anos 2010: reflexões sobre horizontalidade e as tecnologias digitais da informação e comunicação
}

\author{
Collectives and the 2010 protest cycle: reflections on horizontality \\ and digital information and communication technologies
}

Colectivos y el ciclo de protesta de 2010: reflexiones sobre la horizontalidad y las tecnologías digitales de la información

y la comunicación

Recebido em 04-07-2020

Modificado em 13-10-2020

Aceito para publicação em 04-11-2020

\section{Caio Becsi Valiengo}

ORCID: 0000-0002-5623-2447

Doutorando em Ciências Humanas e Sociais na Universidade Federal do ABC (UFABC), Brasil. Mestre em Administração Pública e Governo pela Fundação Getúlio Vargas (FGV), Brasil. E-mail: caio.valiengo@gmail.com

\section{Marilia Jahnel de Oliveira}

ORCID: 0000-0002-7161-4574

Mestre em Ciências Humanas e Sociais na Universidade Federal do ABC (UFABC), Brasil. E-mail: mariliajahnel@gmail.com

\section{Resumo}

Na última década, os grupos autodenominados "coletivos" passaram a ter visibilidade no cenário das mobilizações políticas e das pesquisas acadêmicas, trazendo desafios analíticos ao campo da ação coletiva, tendo em vista a complexidade e a pluralidade encontradas neles. O objetivo deste artigo é refletir sobre a construção de formas de organização horizontais e colaborativas dos coletivos e sobre o uso que fazem das tecnologias digitais da informação e comunicação (TDICs), bem como sobre a relação entre esses dois aspectos. As práticas organizativas e de atuação política desses grupos são analisadas a partir de material resultante de pesquisa realizada com cinco coletivos que atuam na cidade de São Paulo em diálogo com uma retomada histórica do ciclo de protestos dos anos 2010, apresentando uma perspectiva histórica e processual das lutas coletivas. O debate sobre a relação entre horizontalidade, TDICs e formas de liderança busca analisar a construção de práticas horizontais e colaborativas, indicando convergências entre as experiências do ciclo e as práticas dos coletivos, e contribui para a reflexão sobre o cenário contemporâneo de ação coletiva.

Palavras-chave: Ciclo de protestos; coletivos; horizontalidade; tecnologias digitais da informação e comunicação. 


\section{Introdução}

O objetivo deste artigo é refletir sobre a construção de formas de organização horizontais e colaborativas dos coletivos e sobre o uso que fazem das tecnologias digitais da informação e comunicação (TDICs), bem como sobre a relação entre esses dois aspectos. Para isso, realiza-se uma análise das práticas organizativas e de atuação política de grupos que se autodenominam "coletivo" a partir de uma retomada histórica do ciclo de protestos dos anos 2010.

As intensas mudanças no capitalismo global, especialmente os efeitos das novas tecnologias digitais nos processos de produção, socialização, subjetivação e ação coletiva, têm gerado crises e convulsões nos sistemas democráticos em todo o planeta e novos repertórios de resistência têm sido construídos por movimentos sociais, ativistas e indivíduos organizados em rede. Por conta disso, nas últimas décadas, o campo de pesquisa sobre ação coletiva e movimentos sociais tem se deparado com inúmeros desafios analíticos, tendo em vista as transformações ocorridas nos processos de luta política, tanto em nível local como global.

O ciclo de protestos de 2010 se inicia globalmente com a Primavera Árabe no Oriente Médio e no norte da África e segue com os movimentos de indignação em toda a Europa e com os movimentos Occupy nos Estados Unidos. O Brasil integra esse ciclo mais marcadamente com as Jornadas de Junho de 2013, com os protestos contra grandes eventos como as Olimpíadas e a Copa do Mundo e com as manifestações contra e a favor do golpe midiático-parlamentar contra a presidenta eleita Dilma Rousseff. Além desses, também é importante considerar o movimento dos Secundaristas e a chamada Primavera Feminista, iniciados em 2015. Esse ciclo de protestos pode ser entendido como parte de um fenômeno histórico mais amplo de reação à crise global do capitalismo, com expressões tanto de emancipação social quanto de reações populistas (Jappe, 2020), que perdura até hoje ${ }^{1}$ e cujos significados políticos e analíticos ainda estão em disputa.

Nesse contexto, novas formas de ação coletiva passaram a ganhar destaque, dentre elas, os "coletivos". A denominação "coletivo", no entanto, não é novidade no campo da ação coletiva. Bassani (2016), ao discutir a atuação dos coletivos formados no início do século XXI em São Paulo, retomou os grupos de arte pública dos anos 1980 que eram denominados “coletivos" por suas práticas colaborativas entre diversos artistas que realizavam intervenções

\footnotetext{
${ }^{1}$ Apenas para exemplificar, entre 2019 e 2020, ocorreram manifestações massivas no Chile, Colômbia, Equador, Argélia, Sudão, França, Líbano, Iraque, Irã e Hong Kong (Jappe, 2020).
} 
no espaço público e associavam-se aos movimentos sociais vinculados às questões urbanas. Outro exemplo importante é o Coletivo Nacional da Mulher do Movimento dos Trabalhadores Rurais Sem Terra (MST), criado em 1996, e renomeado em 1999 de Coletivo Nacional de Gênero que atua dentro do MST. Entretanto, os coletivos têm despertado especial atenção de pesquisadores e pesquisadoras na última década, pois há uma pluralidade de grupos que assim se autodenominam. Além disso, os coletivos acionam práticas organizativas e de atuação que os afastam de outras ações coletivas, tais como partidos, sindicatos e determinados movimentos sociais, e, com isso, desvelam reflexões sobre formas de organização e atuação política coletiva contemporâneas.

Os coletivos ganharam relevância, principalmente, em estudos que analisam a participação política de jovens e em análises sobre a conjuntura brasileira dos últimos anos, mais especificamente a partir de 2013, em relação às grandes manifestações de rua vinculadas à intensa atuação nas redes sociais que ocorreram nesse período no Brasil (Gohn, 2016, 2017, 2018; Maia, 2013; Peralva; Figeac; Paton; Nogueira, 2017; Perez, 2017, 2019; Perez; Souza, 2017; Santos, 2017). Um panorama sobre a produção acadêmica que faz referência direta aos coletivos verificou a existência de um esforço de conceituação desse termo, abordando os aspectos que são apontados para caracterizá-lo, e demonstrou que a definição dessa forma de ação coletiva ainda está em construção (Jahnel, 2019).

A diversidade das experiências dos coletivos dificulta a elaboração de uma definição conceitual que abarque a multiplicidade dos grupos que se reconhecem enquanto tal e problematiza a capacidade explicativa dos marcos analíticos utilizados diante da complexidade do fenômeno. Ao considerarmos as ações coletivas e os movimentos sociais como fenômenos históricos decorrentes de lutas sociais que se transformam com as mudanças estruturais e conjunturais da sociedade, eles são objetos de estudo permanente (Gohn, 2014). As reconfigurações das práticas sociais exigem constante reformulação das categorias analíticas e esforço dos olhares acadêmicos.

A relação entre as TDICs, especialmente a internet, com os processos políticos têm gerado intensos debates nos últimos 30 anos. Para dar conta da compreensão dessas questões, há um campo específico para o seu estudo no país, como afirmam Silveira, Braga e Penteado (2014):

[...] postulando que há, sim, um campo específico de estudos sobre a internet nas Ciências Sociais contemporâneas, e que esse novo campo de reflexão tem uma natureza intrinsecamente interdisciplinar, abrangendo contribuições de vários ramos das Ciências Sociais no sentido estrito do termo (Antropologia, Ciência Política e 
Sociologia) mas também de disciplinas co-irmãs tais como comunicação social, administração pública, para não falar das ciências da computação e da informática, dentre outras (Silveira; Braga; Penteado, 2014:6).

Além do uso das TDICs por movimentos já existentes, as tecnologias também proporcionaram a emergência de novos movimentos sociais e novas formas de ativismo. (Machado, 2007:248-249) Um subcampo de pesquisa foi desenvolvido para compreender especificamente o ciberativismo, que busca tanto compreender as práticas hackers e cyberpunks e também aborda as novas formas de mobilização e ativismo, nas quais indivíduos e grupos têm suas ações políticas potencializadas pelos ambientes midiáticos e descentralizados da internet (Araújo, 2011:3) e recorrem a plataformas de mídias sociais amplamente utilizadas como Facebook, Twitter, Youtube, Instagram, entre outras (Teixeira; Zanini; Meneses, 2017:13). É importante reforçar que não é o fato de fazer o uso das ferramentas digitais de comunicação o que torna os seus usuários ciberativistas, mas o uso engajado e sistemático desses recursos ciberespaciais (Milhomens, 2014:69).

A multiplicidade de sujeitos políticos contemporâneos, com suas especificidades no campo da ação coletiva, tem demandado de pesquisadores novos olhares e chaves interpretativas para o entendimento dos fenômenos das últimas décadas. Tomem-se como exemplos os debates sobre ação coletiva e ação conectiva (Bennet, Segerberg, 2012, Bennet, Segerberg, Walker, 2014), a construção de novos tipos de liderança e formatos organizativos (Gerbaudo, 2014, no prelo) e a qualidade e alcance de novos tipos de ativismos mediados tecnologicamente (Gladwell, 2010, Morozov, 2011, Scholz, 2010).

Ao olhar para a produção da área de movimentos sociais no Brasil nos últimos 30 anos, Bringel (2015) traça relações entre o repertório de ação dos movimentos sociais e os repertórios de interpretação dos intelectuais e aponta para a alta volatilidade das interpretações desse campo. Segundo o autor, essa oscilação "impede a construção permanente de acúmulos coletivos orientados por questões teóricas comuns (que podem e devem ser respondidas de maneira diferenciada)" (Bringel; Teixeira, 2015:48).

Esse artigo faz uso do conceito de repertório para analisar as práticas das ações coletivas, considerando-o um conjunto de formas de articular demandas e reivindicações que é contingente e, por isso, renovado durante os processos históricos. Conforme Alonso (2012):

A palavra repertório identifica um conjunto limitado de rotinas que são aprendidas, compartilhadas e postas em ação por meio de um processo relativamente deliberado de escolha. Repertórios são criações culturais 
aprendidas, mas eles não descendem de filosofia abstrata ou tomam forma como resultado da propaganda política; eles emergem da luta. [...] Em qualquer ponto particular da história, contudo, elas [as pessoas] aprendem apenas um pequeno número de maneiras alternativas de agir coletivamente (Tilly, 1995 apud Alonso, 2012:26).

Os repertórios podem informar como os grupos apresentam-se publicamente enquanto um ator coletivo, por isso, analisar um conjunto de práticas das ações coletivas possibilita conhecer e caracterizar as formas de organização e de ação que se consolidam em determinado período. Embora haja um conjunto de ações possíveis, é o diálogo ativo entre os sujeitos sociopolíticos, baseado na sua inserção na dinâmica do conflito e na conjuntura, que estabelece as práticas, fazeres e discursos acionados pelos coletivos, entendidos como um tipo de ação coletiva. Dito isso, a noção de prática aqui utilizada faz referência ao conceito de repertório, que foi desenvolvido por Charles Tilly para comparar ações coletivas em diferentes períodos históricos, o qual abarca os aspectos organizativos internos e as práticas de atuação que englobam as ações e realizações do coletivo.

Tendo isso em vista, este artigo pretende contribuir para os estudos e interpretações sobre os coletivos, buscando aprofundar as reflexões sobre os modos de fazer desses grupos de mobilização e atuação política, além de localizá-los em um contexto de movimentos e lutas sociais globais ao analisar possíveis interfaces com o ciclo de protestos dos anos 2010. As apresentadas análises têm como referência o material produzido, ao longo de 2019, a partir de entrevistas semiestruturadas realizadas com cinco coletivos que atuam nos seguintes temas: 1) universitário, que aborda a questão racial, pautando o debate identitário face à implementação de cotas raciais e/ou outros mecanismos que ampliaram a entrada de negros e negras no ensino superior; 2) feminista, em reconhecimento à "Primavera das mulheres ou feminista" 2 e seus desdobramentos; 3) de cultura digital, em referência ao papel atribuído às tecnologias de informação e comunicação, especialmente a internet e as redes sociais, nas disputas políticas recentes; 4) direito à cidade, tema transversal das manifestações de junho de Estilística da Língua Portuguesa 2013, que engloba a demanda por acesso e qualidade dos serviços públicos e por processos participativos na gestão das cidades e no orçamento público; e 5) intervenção urbana, tendo em vista que já na década de 1990 grupos que debatiam a arte pública e os processos de autoria colaborativa autodenominaram-se "coletivos", sendo possível relacioná-

\footnotetext{
${ }^{2}$ A Primavera das mulheres ou primavera feminista refere-se à mobilização que reuniu milhares de mulheres nas ruas em 2015, a qual está associada a um forte ativismo nas redes sociais (Dutra, 2018; Ribeiro; O'Dwyer; Heilborn, 2018).
} 
los com a formação dos coletivos contemporâneos (Bassani, 2016).

Após esta introdução, a primeira seção apresenta características e reflexões sobre ações coletivas das últimas décadas, a partir de uma perspectiva histórica e processual das lutas coletivas. A segunda seção trata diretamente da construção de práticas horizontais e colaborativas, bem como dos limites e tensões encontrados pelos coletivos nesse processo, e aborda, ainda, o uso das TDICs na constituição desses grupos. A terceira parte traz uma análise das conexões entre o uso das TDICs e as formas de organização e de atuação baseadas na horizontalidade e na colaboração, conectando as características encontradas nos movimentos do ciclo e nos coletivos. Por fim, segue a conclusão do artigo acompanhada de apontamentos para a continuidade dos estudos desse campo.

\section{$O$ ciclo de protestos dos anos 2010}

Para compreender o ciclo de protestos dos anos 2010, é importante retomar alguns dos elementos do ciclo que o antecede, considerando o zapatismo e o movimento altermundista (também chamado de antiglobalização), buscando uma perspectiva histórica e processual das lutas coletivas. Nas décadas de 1990 e 2000, a luta de resistência à globalização neoliberal conferiu caráter internacional aos movimentos sociais. Seu repertório abrangeu desde o uso pioneiro das então novas tecnologias digitais, especialmente da internet, pelo movimento zapatista, à pluralidade de táticas do movimento altermundista e organizou a resistência ao processo de globalização capitalista articulando as singularidades de lutas locais com o global através da vinculação de aspectos neoliberais encontrados em diversos territórios com os impactos negativos na vida da população.

A amplitude e convergência das resistências mundiais do período, que tiveram seu auge nos processos vitoriosos do Exército Zapatista de Libertação Nacional (EZLN) frente ao governo mexicano e nos processos de construção do Fórum Social Mundial, resultaram da atuação em rede que permitiu ações planejadas que ocorreram em diversos países simultaneamente, tanto pela conexão permitida pela internet, como pela composição ampla e variada de entidades e movimentos integrantes das mobilizações e campanhas. A articulação nas redes de movimentos permitiu a conexão local e global, internacionalizando o ativismo.

Os anos 2010 iniciam um ciclo de protestos globais referentes ao conjunto de mobilizações que reuniram milhares de pessoas pelas ruas de diversos países e tiveram forte ativismo nas redes sociais digitais. Dentre essas mobilizações que marcaram uma onda de 
resistência e protestos sociais mundiais, destacamos a Primavera Árabe, os Indignados e o Occupy Wall Street.

A Primavera Árabe ${ }^{3}$ faz referência a uma série de protestos e mobilizações que tinha como objetivo a conquista da liberdade de expressão e a melhoria de condições econômicas, que desencadeou a derrubada de décadas de ditaduras e ocorreu em diversos países do Oriente Médio e Norte da África. Compondo essa onda de protestos mundiais, os Indignados espanhóis ${ }^{4}$, ou o movimento $15 \mathrm{M}$, começou organizando-se com núcleos em diferentes cidades que questionavam a falta de democracia representativa sob o lema "Democracia real ya!" e a relação dos partidos políticos com as instituições e suas formas de financiamento. A mobilização expandiu e diversas praças foram ocupadas pelo país, culminando em um grande encontro na Praça Porta do Sol, em Madri. Em reação à crise do capitalismo financeiro de 2008 e às subsequentes respostas governamentais que privilegiaram grandes corporações, seus altos executivos e acionistas em detrimento das centenas de milhares de pessoas que perderam suas casas, o movimento Occupy Wall Street, nos Estados Unidos, ocupou o coração financeiro de Nova Iorque sob o slogan "Nós somos os 99\%", prática que logo se disseminou para outras localidades do país e do mundo sob o registro "Occupy".

O Brasil integra o ciclo de protestos dos anos de 2010 mais marcadamente com as mobilizações de junho de 2013, quando ocorreram grandes manifestações em diversos estados brasileiros. Em São Paulo, assim como em outras cidades, as mobilizações iniciaram-se com um ato do Movimento Passe Livre (MPL) ${ }^{5}$, após o aumento da passagem do transporte público, e, rapidamente, mobilizaram milhares de pessoas. Ao longo dos dias de protestos, diversas pautas e demandas foram colocadas no espaço público das cidades e tomaram uma dimensão não vista anteriormente em outras mobilizações iniciadas pelo grupo. Além do grande número de pessoas presentes nas manifestações, as motivações e pautas foram expandidas e o público foi diversificado a cada novo ato convocado.

\footnotetext{
${ }^{3}$ Integram a Primavera Árabe as revoluções na Tunísia e Egito, as guerras civis na Líbia e na Síria, grandes protestos na Argélia, Bahrein, Djibuti, Iraque, Jordânia, Omã e Iémen e protestos menores no Kuwait, Líbano, Mauritânia, Marrocos, Arábia Saudita, Sudão e Saara Ocidental.

${ }^{4}$ Apesar do destaque ao caso espanhol, outros países europeus se inserem de forma indireta ou direta nesse ciclo de protestos, como a Revolução das Panelas na Islândia em 2008, a resistência à austeridade econômica imposta pela Troika (composta pelo Fundo Monetário Internacional, pela Comissão Europeia e pelo Banco Central Europeu) por parte da Grécia.

${ }^{5}$ Conforme o próprio movimento, “o Movimento Passe Livre (MPL) é um movimento social autônomo, apartidário, horizontal e independente, que luta por um transporte público de verdade, gratuito para o conjunto da população e fora da iniciativa privada". Fonte: https://www.mpl.org.br/, acesso em maio de 2020.
} 
Na esteira das mobilizações das Jornadas de Junho, em 2015 e 2016, os estudantes secundaristas mobilizaram-se diante da proposta de reforma do ensino médio e contra a Proposta de Emenda Constitucional 55, que congelou os investimentos públicos em saúde e educação por 20 anos. Em diversos estados, para posicionar-se contra o plano de reorganização das escolas de ensino médio, tanto pela forma autoritária de sua construção, como também pelo iminente fechamento de diversas unidades de ensino, os Secundaristas realizaram ocupações das escolas e protestos em espaços públicos das cidades. Rapidamente, as escolas ocupadas tornaram-se espaços de vivências colaborativas e compartilhadas de gestão, propiciando uma reflexão sobre os processos participativos internos e externos das escolas e reafirmaram a reivindicação pela educação enquanto um direito público, gratuito e de qualidade ${ }^{6}$.

Nesse contexto, o movimento feminista, que desde 2012 foi impulsionado mundialmente pelas mídias sociais, recolocou a questão de gênero no debate público brasileiro, garantindo importante expressão aos feminismos e às suas diversas demandas (Dutra, 2018; Ribeiro; O’Dwyer; Heilborn, 2018). Indo além do ativismo digital, a luta das mulheres também disputou as ruas. Em reação à tramitação do Projeto de Lei 5069/2013, que atacava os direitos sexuais e reprodutivos das mulheres, diversas manifestações protagonizadas por mulheres se espalharam pelo país, após convocação pela internet, em 2015. Essa mobilização das mulheres, com as campanhas na internet e os atos no espaço público, ficou conhecida como Primavera das Mulheres, em alusão à Primavera Árabe (Brito, 2017).

Em uma análise em perspectiva global, Bringel (2013) situa os protestos ocorridos no Brasil no contexto mais amplo de "indignação global":

[...] o caso brasileiro não pode ser entendido sem levar em consideração o ciclo de protestos que surgiu no mundo nos últimos anos. Embora possa ser discutido se estamos diante de um "ciclo global" de contestações (tal como o vivido com o movimento antiglobalização a partir dos anos 1990) ou simplesmente de uma "coleção" de mobilizações nacionais conectadas regionalmente e globalmente de maneira mais frouxa (e às vezes, inclusive "imaginaria"), o fato é que há várias discussões e elementos transversais que conectam as mobilizações emergentes no Brasil com experiências tão distintas como as ocorridas na Grécia, nos Estados Unidos, na Islândia, na Espanha, na Turquia ou em alguns países do norte da África (Bringel, 2013:3).

\footnotetext{
${ }^{6}$ É importante registrar que as cartilhas do movimento secundarista chileno serviram de modelo e inspiração aos secundaristas brasileiros e foram traduzidas para o português por um membro do coletivo Mal-Educado.
} 
Já Funke e Wolfson (2017) identificam três ondas de protesto ocorridas dos anos 1990 até hoje, sendo a primeira chamada de "onda da justiça global", que incorpora os movimentos da década de 1990 aqui já descritos (zapatismo e altermundismo); uma segunda chamada de "onda da crise", que englobaria a Primavera Árabe, os movimentos antiausteridade e o Occupy Wall Street; e finalmente uma terceira chamada "onda do pós-crise", que diz respeito ao "movimento dos guarda-chuvas" de Taiwan, o Black Lives Matter dos Estados Unidos, além da institucionalização nas disputas partidárias de grupos das ondas anteriores, como o Syriza e Podemos. Os movimentos ocorridos no Brasil são entendidos como parte da segunda onda, a partir do que Gerbaudo (2017) categoriza como "ciber-populismo".

Entre as demandas e os repertórios encontrados no ciclo de protestos dos anos 2010, brevemente apresentados, destacam-se: a retomada da ocupação de espaços públicos das cidades como estratégia de disputa política; o questionamento da democracia representativa e de suas instituições; a centralidade da internet e das tecnologias digitais; e a construção de formas de organização horizontais e práticas colaborativas (Castells, 2013; Gohn, 2014b, 2017; Harvey, 2012; Pinto, 2012; Rolnik, 2013).

A ocupação dos espaços públicos das grandes cidades, como estratégia de disputa política, pautou o direito à cidade, a qualidade dos serviços públicos e reivindicou maior participação da população nas decisões estatais, evidenciando os desgastes da democracia representativa e de suas instituições. A tática de ocupar espaços públicos e fazer outro uso desse lugar com práticas participativas foi um marco do ciclo ao mostrar "como o poder coletivo de corpos no espaço público continua sendo o instrumento mais efetivo de oposição" (Harvey, 2012:61).

Além de ter uma expressão prática de influência sobre o território, a ocupação do espaço público é também simbólica, pois demanda o reconhecimento da presença da população na cidade, em busca de visibilidade e de participação. Ao refletir sobre as Jornadas de Junho de 2013, Rolnik (2013) afirma:

\footnotetext{
Mas hoje o tema da ocupação - no sentido do controle do espaço, mesmo que por um certo período, e, a partir daí a ação direta na gestão de seus fluxos - tem forte ressonância no sentimento, que parece generalizado, do alheamento em relação aos processos decisórios na política e da falta de expressão pública por parte significativa da população (Rolnik, 2013:10).
}

O questionamento sobre os limites da democracia representativa e suas instituições é outro aspecto bastante marcante que está refletido na prática dos próprios movimentos que 
buscaram formas de organização mais horizontais e colaborativas. As grandes manifestações organizadas nesse ciclo de protestos tiveram "como principal característica um claro enfrentamento com os pactos políticos - institucionais vigentes" (Pinto, 2012:135). Cada qual com suas especificidades, esses movimentos expuseram a indignação em relação à ausência da democracia ou seus limites, denunciando que os processos eleitorais e os partidos não representavam os interesses e valores da população, por isso, reivindicaram profundas reformas no sistema eleitoral (Castells, 2013).

Para não reproduzir as práticas da democracia formal às quais se opunham e refletindo também acúmulos passados das experiências dos ciclos que os antecederam, os movimentos experimentaram novas formas de organização e deliberação, de consultas pela internet à deliberação por meio de assembleias gerais, propondo um novo modelo organizacional para orientar as ações e dinâmicas dos grupos.

O uso das TDICs, especialmente da internet e das redes sociais digitais, é uma característica marcante do ciclo de protesto dos anos 2010. Para Kavada (2010), a internet e sua infraestrutura flexível e descentralizada possui uma afinidade especial com formas mais "soltas" de organização que, segundo a autora, caracterizam os movimentos sociais:

\begin{abstract}
Facilitando uma comunicação rápida e barata através de fronteiras geográficas, a Internet pode auxiliar na transformação da insatisfação em ação coletiva massiva de forma rápida e eficiente. Ferramentas online podem ajudar movimentos sociais a disseminar informação, recrutar participantes, organizar, coordenar e tomar decisões. No entanto, essas facilidades e a velocidade da comunicação online não levam necessariamente a redes ativistas duráveis e estáveis, pelo menos não no sentido tradicional (Kavada, 2010:101[Tradução nossa]).
\end{abstract}

A abordagem de Castells (2013), como muitas outras que olharam para a relação entre as redes e as ruas a partir de ações coletivas dos primeiros anos deste século, colocou bastante esperança nas redes de indignação. Para o autor, com a disseminação das tecnologias da informação, a comunicação tem passado por uma profunda transformação tecnológica e organizacional baseada em redes horizontais, interativas, localizadas na internet:

Os movimentos sociais em rede de nossa época são amplamente fundamentados na internet, que é um componente necessário, embora não suficiente, da ação coletiva. As redes sociais digitais baseadas na internet e nas plataformas sem fio são ferramentas decisivas para mobilizar, organizar, deliberar, coordenar e decidir. Mas o papel da internet ultrapassa a instrumentalidade: ela cria as condições para uma forma de prática comum que permite a um movimento sem liderança sobreviver, deliberar, coordenar e expandir-se. Ela protege o movimento da repressão de seus espaços físicos liberados, mantendo a comunicação entre as pessoas do movimento e com a sociedade em geral na longa marcha da mudança social exigida para superar a dominação institucionalizada (Castells, 2013:151). 
Hoje é inegável o potencial que a internet e suas aplicações, como redes sociais e mídias sociais, possuem de multiplicar vozes, romper barreiras geográficas e temporais, garantir a pluralidade de informações e, de fato, criar uma forma de comunicação na qual seus "usuários têm a chance de atuar, simultaneamente, como produtores, emissores e receptores de ideias e conhecimentos, dependendo de habilidades técnicas e lastros culturais" (Moraes, 2009:239). No entanto, a presença das tecnologias de comunicação na atuação das ações coletivas não deve ser entendida como fator causal das ações e mobilizações.

Os conflitos, contradições e desigualdades sociais inerentes ao capitalismo, aprofundados com o capitalismo neoliberal, devem ser considerados fatores decisivos para o desencadeamento da organização de ações coletivas que possam manifestar e expressar a insatisfação de grupos e indivíduos. Como refletem Silveira, Penteado e Braga: Se é verdade que não devemos cair no extremo de um "determinismo tecnológico"
segundo o qual as inovações que ocorrem no sistema econômico e nos meios de
comunicação geram automaticamente novas modalidades de ação coletiva e de
comportamentos humanos, sem a mediação das escolhas estratégicas dos atores
sociais, também não devemos cair no outro extremo de deixar de levar em conta os
impactos de tais inovações tecnológicas nas formas de sociabilidade
contemporâneas (Silveira; Penteado; Braga, 2014:5).

Olhares críticos buscaram enxergar os limites da rede, como o alcance limitado da tecnologia a todas as pessoas, especialmente as classes subalternas; o fato de os sites dos grandes meios de comunicação convencionais (rádio, televisão e jornais impressos) ainda serem os mais acessados e com maior alcance na rede (Scholz, 2010), padecendo das mesmas críticas possíveis da mídia hegemônica offline; e também o surgimento das novas grandes corporações midiáticas, como Google e Facebook, que garantem uma ilusão de liberdade na web.

Outro elemento marcante do ciclo de protestos dos anos 2010 é a busca pela construção e a narrativa de formas de organização baseadas na horizontalidade e de práticas colaborativas no desenvolvimento das tarefas do cotidiano dos movimentos citados, que estão vinculadas aos questionamentos e demandas colocadas por eles. Diante da desconfiança das lideranças políticas organizadas e o exercício diário da radicalidade da democracia participativa nos espaços de organização, os movimentos não reconheciam líderes, nem portavozes.

A rejeição da liderança também resultou de uma profunda desconfiança em relação a qualquer liderança política organizada, depois de observarem a corrupção e o cinismo que caracterizavam os governos e partidos tradicionais (Castells, 2013:102). 
Como já foi visto, os movimentos experimentaram formas de democracia deliberativa, por meio de consultas pela internet e gestão compartilhada do espaço escolar, tomando por exemplo as lutas secundaristas. Além disso, exerciam a horizontalidade por meio das assembleias gerais que aconteciam nos espaços ocupados.

As características do ciclo de protestos dos anos 2010 aqui elencadas, nomeadamente a retomada da ocupação de espaços públicos, o questionamento da democracia representativa, a centralidade das TDICs e as formas de organização e práticas horizontais e colaborativas, dialogam com a caracterização das práticas de organização de atuação dos coletivos, as quais serão exploradas na próxima seção.

\section{Coletivos: práticas de atuação e organização}

Para refletir sobre as práticas de organização e de atuação, a fim de contribuir para a caracterização de grupos que se autodenominam "coletivos", foram realizadas pesquisas empíricas com coletivos que atuam na cidade de São Paulo em uma pluralidade de temas conectados à emancipação social, como igualdade racial, feminismo, democratização da internet e da comunicação, fomento à cultura, direito à cidade, dentre outros. Esses grupos atuam tanto nos espaços públicos da cidade como em ambientes mais restritos, como o universitário.

As práticas políticas acontecem nas redes e nas ruas, de formas complementares, utilizando-se de repertórios variados, como ocupação do espaço público, intervenções artísticas, disputas jurídicas, compartilhamento e divulgação de conhecimento, produção de conteúdo, muitas vezes com diálogo direto ou indireto com a política institucional, seja via editais públicos seja via financiamento advindo de instituições do terceiro setor, em maior ou menor intensidade.

Alguns estudos apontam para as redes sociais e mídias digitais como um fator relevante para a constituição dos coletivos (Maia, 2013; Gohn, 2017), mas é preciso ressalvar se esse aspecto pode ser considerado um diferencial dos grupos autodenominados "coletivos", já que as interfaces das ações coletivas com as TDICs estão inseridas num contexto mais amplo da sociedade em rede. O uso das TDICs atravessa as práticas organizativas e de atuação dos coletivos de diversas maneiras. As ferramentas digitais são utilizadas para trocas de informação, tomada de decisões, e contato com outros coletivos para a elaboração de 
atividades em parceria e podem colaborar para a divulgação de ações e de conteúdos por eles produzidos, conteúdos que dialogam com o projeto político de cada coletivo.

Em relação às práticas internas de organização dos grupos, as mídias digitais são indispensáveis para os processos de comunicação entre integrantes dos coletivos, sendo o WhatsApp e o Telegram as ferramentas mais utilizadas. Ao possibilitarem um contato instantâneo e simultâneo entre as pessoas que formam o coletivo, as redes sociais são utilizadas como ferramentas para agendar encontros, produzir conteúdo e encaminhar e deliberar questões conjuntamente.

Entretanto, a utilização de aplicativos de troca de mensagens como principal ferramenta de comunicação interna dos integrantes dos coletivos gera reflexões e problematizações por parte de seus membros. Muitos acreditam que a interlocução fica prejudicada devido aos ruídos na comunicação, gerando conflitos internos e disputas desnecessárias, e preferem encontros presenciais para garantir uma construção mais colaborativa, propositiva e menos conflituosa. As redes sociais dos coletivos são comumente usadas para divulgação de ações de parceiros. Essa é uma prática que funciona como uma rede de troca de mobilização entre os coletivos que desenvolvem atividades em conjunto ou entre os quais há sintonia dos objetivos políticos, gerando fortalecimento mútuo.

Um dos principais usos estratégicos das TDICs pelos coletivos diz respeito ao fomento e à circulação de conhecimentos, experiências e conteúdos temáticos que dialogam diretamente com seus campos de atuação. A lógica colaborativa das redes ressoa com uma visão compartilhada dos fazeres dos grupos que está diretamente relacionada à autodenominação "coletivo". Para os grupos que se entendem no campo político anticapitalista, soma-se uma camada conceitual dessa prática, pois a organização colaborativa permite exercitar formas que sejam opostas à lógica individualista e competitiva do capitalismo.

A possibilidade de divulgação de conteúdos nas redes e, consequentemente, a circulação de seus valores e objetivos reafirmam que as mídias digitais se configuram como espaços de disputa política. No entanto, com exceção dos grupos que se consideram no campo do ciberativismo, os coletivos costumam fazer um uso instrumental das tecnologias, muitas vezes com foco nas redes sociais digitais, não atribuindo centralidade às disputas estruturais das TDICs. De maneira geral, as ações offline possuem destaque em seu leque de repertórios.

Essa característica dialoga diretamente com a reflexão realizada por Sancho (2018), quando compara o uso das TDICs nos diferentes ciclos de protestos aqui analisados. Para a 
autora, o ciclo dos anos 1990 e 2000 pode ser considerado como a etapa das "redes ativistas", que se contrapõem aos veículos hegemônicos de comunicação e produzem as próprias narrativas sobre os protestos, nas quais diversos e pequenos meios de comunicação autogeridos se conectam entre si para "formar redes contrapúblicas mais amplas e deslocalizadas" (Sancho, 2018:357). Já o ciclo dos anos 2010 é a fase das "multidões conectadas", na qual a participação se torna mais distribuída, tendo como veículo as redes sociais digitais, sem precisar da mediação de coletivos de comunicação, como no ciclo anterior. Para a autora:

\begin{abstract}
Algo diferente ocorre com as "multidões conectadas" a partir de 2011, nas quais quem participa das manifestações carrega suas extensões eletrônicas e não necessariamente está previamente politizado, nem responde ao chamado de uma organização, nem desenvolve um canal de comunicação próprio. Ao contrário, saem à rua e agem a partir de seus espaços de comunicação cotidianos, mesmo que sejam canais politicamente questionáveis, como a rede social privativa Facebook ou mesmo o Twitter (Sancho, 2018:367).
\end{abstract}

Dessa forma, por mais que a as TDICs, especialmente a internet, possuam o potencial para e contem com uma história de práticas colaborativas, para grande parte dos coletivos elas funcionam apenas como ferramenta de suporte cotidiano para as suas ações. Não há centralidade do debate político sobre as tecnologias na constituição de seus projetos políticos e de suas práticas de atuação, tampouco consistindo em um diferencial nas práticas organizativas desses grupos, apontando para um uso mais instrumental, apenas como suporte de comunicação.

A construção de práticas horizontais e colaborativas, assim como a centralidade das TDICs, é outro aspecto apontado como relevante para a constituição dos coletivos pelos estudos que se debruçaram sobre essa ação coletiva (Aderaldo, 2016; Gohn, 2018; Maia, 2013; Santos, 2017). Os procedimentos adotados para a divisão de tarefas que articulam disponibilidade de tempo, habilidades específicas e manifestação voluntária de seus integrantes indicam a tentativa de construir um ambiente menos hierárquico no processo dos afazeres dos coletivos. As práticas decisórias que são pautadas por deliberações consensuais ou por votação também seguem a tendência de horizontalidade.

Os coletivos reconhecem o desafio cotidiano e os limites da atuação orientada por uma perspectiva horizontal e colaborativa, como a dificuldade em conseguir finalizar as tarefas por não haver a possibilidade de cobranças mútuas entre os integrantes. Diante dessa constatação, alguns coletivos estabelecem estratégias como um rodízio entre as pessoas para definir quem 
vai coordenar cada ação ou projeto específico. Dessa forma, o membro responsável pela coordenação está autorizado a cobrar os outros e deve garantir que as informações circulem no grupo, para assegurar a execução da tarefa e o compartilhamento do processo, em busca de uma prática colaborativa. Outra questão difícil de ser equacionada é o equilíbrio do tempo de dedicação entre os integrantes para a realização de projetos e ações.

É importante pontuar que a questão da horizontalidade está relacionada à ideia de liderança (tanto por sua ausência quanto por sua ressignificação), mas também está vinculada ao fazer colaborativo, no qual não há diferenciação dos papéis dos membros dos coletivos em razão de suas habilidades ou funções desempenhadas (é melhor que não sejam fixas). Ainda, há a valorização pela participação direta dos integrantes nos processos, buscando exercitar no cotidiano dos grupos os valores e ideais que orientam o objetivo político dos coletivos. As problematizações indicam limites e tensões nos processos de construção de práticas organizativas e de atuação que sejam mais colaborativas e horizontais, salientando a complexidade desses espaços.

\section{Horizontalidade e TDICs}

Bennet e Sergerberg (2012) se tornaram uma referência importante em seu esforço de pontuar analiticamente as diferenças entre a ação coletiva convencional e a ação coletiva digitalmente mediada, batizada pelos autores de "ação conectiva", cujas diferenças se encontram em suas lógicas organizacionais, principalmente no papel da comunicação como um princípio organizacional. Se nos movimentos sociais e ações de protestos pautados na lógica da ação coletiva é possível identificar rapidamente organizações, lideranças e identidades coletivas, o mesmo não aconteceria na ação conectiva. Nesse caso, os indivíduos mobilizados em rede estariam desprovidos de elementos considerados centrais para a sua conceitualização como ação coletiva (Teixeira; Zanini; Meneses, 2017:2).

Diferentemente da ação coletiva convencional, que normalmente demandaria de seus participantes tomadas de decisões mais difíceis e a adoção de identidades sociais e coletivas mais "trabalhosas", que por sua vez exigem mais educação, pressão, socialização e um maior nível de formalização e utilização de recursos, as redes de ação conectiva são conjuntos de processos mais individualizados e organizados tecnologicamente que resultam em ações sem a necessidade da criação de identidades coletivas ou de níveis e esforços organizacionais 
robustos para responder a determinadas oportunidades políticas. Elas podem variar em termos de estabilidade, escala e coerência (Bennet; Segerberg, 2012:750).

Um primeiro contraponto a essa formulação consiste na ideia de que mesmo nos fenômenos considerados como ação conectiva pelos autores, ainda seria possível identificar claros elementos identitários nessas ações aparentemente individualizadas e fluídas. Teixeira, Zanini e Meneses (2017:7), ao analisar a atuação de grupos e ativistas feministas na internet, afirmam que ainda que se caracterizem como fenômenos coletivos mais fluidos, estes não deixam de ter fortes impactos sobre a vida social. Além disso, argumentam que analisar os processos neles ocorridos como ações individualizadas daria origem a uma teorização insuficiente dos processos dos movimentos sociais contemporâneos.

As tecnologias digitais são centrais nos processos da ação conectiva, pois possibilitam a personalização da comunicação de determinada causa ou agenda política para diferentes pessoas, o que permitiria formações de larga escala. Ao invés de focar em plataformas específicas, como Twitter e Facebook, uma vez que elas mudam, surgem e desaparecem ao longo do tempo, os autores preferem chamar de "tecnologias de costura de redes" essas plataformas e dispositivos (Bennet; Segerberg; Walker, 2014:238).

Essas tecnologias de costura permitiriam comunicações personalizadas que se baseiam em dois elementos: (a) conteúdo político no formato de ideias facilmente personalizáveis, como no exemplo do "somos o 99\%" do Ocuppy Wall Street ou do "não nos representam" dos Indignados espanhóis, e (b) a existência de tecnologias de comunicação pessoais que permitem o compartilhamento desse conteúdo político, de forma que o próprio processo de comunicação gera novas personalizações conforme as pessoas compartilham informações com seus amigos e conhecidos (Bennet; Segerberg, 2012:744-745).

Apesar das diferenças, os autores alertam que as fronteiras entre a ação coletiva e a ação conectiva muitas vezes se sobrepõem. No entanto, ainda é possível diferenciá-las a partir de seus princípios organizacionais (Bennet; Segerberg, 2012:754). Algumas das questões norteadoras dos autores são as seguintes: como ações conectivas de larga escala conseguem manter algum tipo de organização coerente? Se não podem contar com estruturas de lideranças bem definidas, quais os mecanismos associativistas que criam e suportam esse tipo de organização? Para responder a essas perguntas, os autores produziram um enquadramento

\footnotetext{
${ }^{7}$ Do original "network stitching technologies".
} 
analítico que busca examinar processos organizacionais básicos da ação conectiva, com foco em ações comunicativas (Bennet; Segerberg; Walker, 2014:234).

Esse quadro analítico é inspirado nas experiências de produção em pares (peer production), típica de grupos hackers e de softwares livres, nas quais indivíduos participam de maneira voluntária de projetos, conforme as suas habilidades e disponibilidades. Estas experiências demandam algum grau de voluntarismo de seus integrantes, conforme os autores notam:

[...] participantes idealmente contribuem com o projeto de maneira modular e granular e colaboram na formulação das condições de ação de forma que os projetos se constroem por meio de autosseleção e descentralização, ao invés de coerção e tarefas hierarquicamente atribuídas (Bennet; Segerberg; Walker, 2014:235 [tradução nossa]).

Apesar das evidentes diferenças entre ações conectivas e projetos de produção em pares, os autores acreditam que é possível identificar microssequências de diferentes rotinas típicas da produção em pares que constituiriam na organização de "pacotes comunicacionais" utilizados por indivíduos e grupos na ação conectiva e que funcionariam como produtores de ordem na multidão (Bennet; Segerberg; Walker, 2014:237). Em contraponto, Gerbaudo (2014:264) assinala que ao focar nos microprocessos organizacionais, os autores deixam de capturar novas formas organizacionais, nas quais processos de construção de identidade, solidariedade coletiva e de liderança ainda continuam tão relevantes quanto nas práticas da ação coletiva. $\mathrm{O}$ autor reforça que é necessário superar a visão agregativa dos movimentos sociais, como se fossem a soma de milhares de pequenos atos, e compreender que a coerência das comunicações de protesto se origina de fenômenos coletivos, especialmente por meio da criação de identidades comuns e culturas de protesto e novas formas de liderança coletiva.

A temática da liderança é retomada de maneira central em alguns debates mais gerais sobre a cultura da internet, uma vez que muitos fenômenos de massa, como o compartilhamento de memes e a formação de grupos em torno dos mais variados temas, parecem ser espontâneos, aparentemente sem líderes, e muitas vezes surgem sem um motivo particular. Para Hwang (2010:121), esses fenômenos são surpreendentes quando vistos de uma perspectiva tradicional de liderança e dos métodos lentos e deliberativos normalmente associados à mobilização de indivíduos por uma causa.

Tendo em vista o panorama histórico e a análise das práticas dos coletivos apresentadas anteriormente, a presente seção dedica-se a refletir sobre as relações entre as TIDCs e a horizontalidade. O discurso de horizontalidade como princípio de organização dos 
grupos de ação coletiva geralmente é interpretado como a "ausência de lideranças". Por exemplo, diversas análises sobre a participação do MPL nos atos de junho de 2013 destacaram o fato de esse grupo não reconhecer ou identificar uma liderança entre os seus membros, o que dificultaria a negociação com o poder público. Esse fato também reapareceu nas interpretações acerca do movimento dos secundaristas.

A temática da liderança é retomada de maneira central em alguns debates mais gerais sobre a cultura da internet, uma vez que muitos fenômenos de massa, como o compartilhamento de memes e a formação de grupos em torno dos mais variados temas, parecem ser espontâneos, aparentemente sem líderes, e muitas vezes surgem sem um motivo particular (Hwang, 2010). Trazendo este debate para a realidade da ação coletiva contemporânea através da análise das experiências do ciclo de protestos dos anos 2010, especificamente da Primavera Árabe, do 15M na Espanha e do Occupy Wall Street nos Estados Unidos, Gerbaudo (no prelo), em seu livro "Redes e ruas: Mídias sociais e ativismo contemporâneo" defende que o uso de Internet e redes sociais pelos movimentos sociais não os tornaria sem líderes ou os organizaria de maneira horizontal automaticamente, mas sim construiria novas formas de liderança suave ou liderança coreográfica.

O alvo da crítica do autor são as teses e discursos que afirmam que os movimentos sociais e o ativismo contemporâneo são marcados pela ausência de liderança e pela ideologia da horizontalidade, que se baseia na ideia de que dada a disponibilidade das TDICs para o uso pelos movimentos sociais, estes não precisariam mais se basear em estruturas lineares de comando que são características de organizações burocráticas, mas sim na inteligência da multidão negriana, em que ninguém e todos seriam líderes. Para compreender esse fenômeno, o autor afirma que indivíduos organizados pelas redes sociais produzem uma "coreografia da assembleia" na qual se criam processos simbólicos de construção de espaços públicos, o que facilitaria e guiaria a união de agrupamentos altamente individualizados e dispersos:

\footnotetext{
A adoção do termo "coreografia" serve para indicar que o processo de construção simbólica do espaço público, apesar do caráter participativo e das reivindicações tecnolibertárias da cultura de protesto, não foi totalmente "espontâneo" ou "sem liderança", como muitos especialistas, jornalistas, ativistas e acadêmicos sugeriram (Gerbaudo, no prelo).
}

Se ainda nos movimentos altermundistas as ferramentas de comunicação eram utilizadas conforme as estruturas organizacionais dos grupos, os movimentos analisados no 
ciclo de protestos dos anos 2010 inverteriam a fórmula: as estruturas organizacionais se conformam às ferramentas de comunicação. Nesse sentido:

É a comunicação que organiza, e não a organização que se comunica. Como corolário, os "comunicadores" também se tornam automaticamente "organizadores", dada a influência que podem ter por meio de suas comunicações no desenrolar da ação coletiva (Gerbaudo, no prelo).

Ou seja, por mais distribuída que essa nova forma de liderança possa ser, ela ainda conta com a presença de indivíduos e grupos, muitas vezes anônimos ou sob um nome coletivo, que produzem grande parte das ações comunicativas das ações de protesto e que possuem capacidade de influenciar de forma significativa os rumos dos movimentos sociais tecnologicamente mediados.

Ainda, Gerbaudo (no prelo) reforça que essas novas formas de lideranças não negam o potencial e a capacidade dos movimentos sociais mediados tecnologicamente de criar espaços genuínos de participação e expressão. Além disso, essas novas formas de liderança ainda ocorreriam de forma paralela às lideranças presenciais em nível de rua. Uma vez que os movimentos vão para as ruas e para os espaços públicos, eles tendem a abrir espaço para outros tipos de lideranças, muitas vezes mais convencionais, com determinados indivíduos ou grupos com capacidade de influência e direção.

\section{Considerações finais}

A partir das experiências brasileiras no ciclo de protestos dos anos 2010, os grupos autodenominados "coletivos" passaram a ter visibilidade no cenário das mobilizações políticas e das pesquisas acadêmicas. O fenômeno dos coletivos traz desafios analíticos ao campo da ação coletiva, tendo em vista a complexidade e a pluralidade encontradas neles.

Dentre essa multiplicidade, um elemento comum relacionado à caracterização dos coletivos é a construção de práticas horizontais e colaborativas, frequentemente atravessada por tensões e limites nos fazeres cotidianos. Essas práticas dialogam com aspectos do ciclo de protestos dos anos 2010, cuja retomada teve como objetivo apresentar uma perspectiva histórica e processual das lutas coletivas.

A despeito das particularidades das mobilizações e do contexto social, econômico e político dos países do ciclo de 2010 e dos desdobramentos e consequências de cada processo político, pode-se constatar que existem características que atravessam as experiências do ciclo 
e as práticas dos coletivos. Sendo assim, o debate sobre a relação entre horizontalidade, TDICs e formas de liderança contribui para a análise sobre a construção de práticas horizontais e colaborativas e indica convergências e aproximações que servem à reflexão sobre o cenário contemporâneo de ação coletiva.

\section{Referências}

ALONSO, Angela (2012), "Repertório segundo Charles Tilly: história de um conceito". Sociologia \& Antropologia, Rio de Janeiro, v. 2, n. 3, pp. 21-41 [Consult. 12-10-2020]. Disponível em https://www.scielo.br/pdf/sant/v2n3/2238-3875-sant-02-03-0021.pdf

ADERALDO, Guilhermo (2016), "Entre imagens e imaginários: estética e política nas intervenções visuais/audiovisuais de coletivos culturais paulistanos", in L. Kowarick; H. Frúgoli (Orgs.), Pluralidade Urbana em São Paulo. São Paulo, Editora 34, pp. 55-79.

ARAÚJO, Willian (2011), "Ciberativismo: levantamento do estado da arte na pesquisa no Brasil". $V$ Simpósio Nacional ABCiber, Florianópolis, SC [Consult. 12-10-2020]. Disponível em http://abciber.org.br/simposio2011/anais/Trabalhos/artigos/Eixo\%207/10.E7/193-300-1-RV.pdf

BASSANI, Jorge (2016), Série Coletivos Culturais. [Consult. 18-07-2020]. Disponível em:http://www.itaucultural.org.br/jorge-bassani-serie-coletivos-culturais

BENNETT, Lance; SEGERBERG, Alexandra (2012), "The Logic of Connective Action." Information, Communication \& Society, n. 15, v. 5, pp. 739-768 [Consult. 12-10-2020]. Disponível em https://doi.org/10.1080/1369118X.2012.670661

BENNET, Lance; SEGERBERG, Alexandra; WALKERS, Shawn (2014), "Organization in the crowd: peer production in large-scale networked protests." Information, Communication \& Society, v. 17, n. 2, pp. 232-260. Disponível em https://doi.org/10.1080/1369118X.2013.870379 [Consult. 12-102020].

BRINGEL, Breno (2013), "Sentidos e tendências do levante brasileiro de 2013". Núcleo de Estudos de Teoria Social e América Latina (NETSAL), IESP/UERJ, pp. 16-29. Disponível em https://www.academia.edu/10068329/_2013_As_Jornadas_de_Junho_em_perspectiva_global [Consult. 10-04-2020].

BRINGEL, Breno; TEIXEIRA, Marco Antonio (2015), "Repertórios de Ação e Repertórios de interpretação: trinta anos de estudos sobre os movimentos sociais no Brasil.”, in. I. Scherer-Warren e L. Luchmann (orgs.) Movimentos Sociais e Engajamento Político, UFSC, pp. 43-76.

BRITO, Priscilla (2017), "Primavera feminista: a internet e as manifestações de mulheres em 2015 no Rio de Janeiro." Seminário Internacional Fazendo Gênero 11. Florianópolis, SC Disponível em http://www.en.wwc2017.eventos.dype.com.br/resources/anais/1499450296_ARQUIVO_Primavera Feminista-ainterneteasmanifestacoesdemulheresem2015noRiodeJaneiro-FazendoGenero.pdf [Consult. 10-05-2020].

CASTELLS, Manuel (2013), Redes de indignação e esperança: movimentos sociais na era da Internet. Rio de Janeiro, Zahar. 
DUTRA, Zeila (2018), "A Primavera das Mulheres: ciberfeminismo e os movimentos feministas". Revista Feminismos, v. 6, n. 2, maio-agosto, pp.19-31 [Consult. 10-05-2020]. Disponível em https://portalseer.ufba.br/index.php/feminismos/article/view/30384

FUNKE, Peter; WOLFSON, Todd (2017), "From Global Justice to Occupy and Podemos: mapping three stages of contemporary activism". TripleC: Communication, Capitalism \& Critique. n. 15 (2), pp. 393-405 [Consult. 12-10-2020]. Disponível em https://doi.org/10.31269/triplec.v15i2.887

GERBAUDO, Paolo (2014), "The persistence of collectivity in digital protest". Information, Communication \& Society, v. 17, n. 2, pp. 264-268 [Consult. 12-10-2020]. Disponível em https://doi.org/10.1080/1369118X.2013.868504

. (2017), "From cyber-autonomism to cyber-populism: an ideological history of digital activism". TripleC: Communication, Capitalism \& Critique. n. 15 (2), pp. 393-405 [Consult. 1210-2020]. Disponível em https://doi.org/10.31269/triplec.v15i2.773

Funilaria.

(no prelo), Redes e ruas: mídias sociais e ativismo contemporâneo. São Paulo, Editora

GLADWELL, Malcom (2010), "Small Change: Why the Revolution Will Not be Tweeted". New Yorker, 4 de outubro [Consult. 26-10-2020].

Disponível em https://www.newyorker.com/magazine/2010/10/04/small-change-malcolm-gladwell

GOHN, Maria da Glória (2014), Teoria dos Movimentos Sociais: paradigmas e clássicos contemporâneos. São Paulo, Loyola.

. (2014b), Sociologia dos Movimentos Sociais. São Paulo, Cortez.

. (2016), "Movimentos Sociais e Movimentos de Coletivos em São Paulo: o papel da política, dos mediadores e da media nas mobilizações, manifestações e protestos nas ruas na atualidade", in $10^{\circ}$ Encontro Associação Brasileira de Ciência Política (ABCP), Belo Horizonte, MG [Consult. 10-05-2020]. Disponível em https://cienciapolitica.org.br/eventos/10o-encontroabcp/anais?page $=23$

. (2017), Manifestações e protestos no Brasil: correntes e contracorrentes na atualidade. São Paulo, Cortez.

. (2018), "Jovens na política na atualidade - uma nova cultura de participação" Caderno CRH, Salvador, v. 31 n. 82, pp. 117-133 [Consult. 10-05-2020]. Disponível em http://www.scielo.br/scielo.php?script=sci_arttext\&pid=S0103-49792018000100117

HARVEY, David (2012), Occupy: movimentos de protesto que tomaram as ruas. São Paulo, Carta Maior e Boitempo.

HWANG, Tim (2010), "Digital Transforms Activism: The Web Ecology Perspective." in M. C. Joyce (Org.) Digital Activism Decoded: The new mechanics of change, New York, Idebate Press, pp. 1732.

JAHNEL, Marilia (2019), Coletivos na cidade de São Paulo: práticas organizativas, práticas de atuação e identidades coletivas. Dissertação (Mestrado em Ciências Humanas e Sociais). PCHS, UFABC, São Bernardo do Campo. 115p.

JAPPE, Anselm (2020), “A obediência morreu?”. Revista Margem Esquerda - Ensaios Marxistas. n. 34, São Paulo, Boitempo, pp. 29-34.

KAVADA, Anastasia (2010), “Activism Transforms Digital: The Social Movement Perspective". in M. C. Joyce (org.) Digital Activism Decoded: The new mechanics of change, New York, Idebate Press, pp. 101-118. 
MACHADO, Jorge (2007), "Ativismo em rede e conexões identitárias: novas perspectivas para os movimentos sociais". Sociologias, Porto Alegre, n. 18, pp. 248-285 [Consult. 10-05-2020]. Disponível em https://doi.org/10.1590/S1517-45222007000200012

MAIA, Gretha (2013), "A juventude e os coletivos: como se articulam as novas formas de expressão política". Revista eletrônica do curso de direito da UFSM, v. 8. n. 1, pp. 58-73 [Consult. 10-052020]. Disponível em https://periodicos.ufsm.br/revistadireito/article/view/8630

MILHOMENS, Lucas (2014), "Ciberativismo na Amazônia: os desafios da militância digital na floresta (2012)”. In: S. A. Silveira; S. Braga; C. Penteado (Orgs.). Cultura, Política e Ativismo nas Redes Digitais. São Paulo, Fundação Perseu Abramo, pp. 51-77 [Consult. 10-05-2020]. Disponível em https://fpabramo.org.br/publicacoes/wp-content/uploads/sites/5/2019/03/RedesDigitais-web.pdf

MORAES, Denis (2009), A batalha da mídia: governos progressistas e políticas de comunicação na América Latina e outros ensaios. Rio de Janeiro, Editora Pão e Rosas.

MOROZOV, Evgeny (2011), The Net Delusion: the dark side of Internet freedom. New York, Public Affairs.

PERALVA, Angelina; FIGEAC, Julien; PATON, Nathalie; NOGUEIRA, Rachel (2017), "O legado de 2013: Coletivos de ativistas e a agenda política brasileira", in $41^{\circ}$ Encontro Anual da ANPOCS, GT 8, Caxambu, MG [Consult. 10-05-2020].

Disponível em https://www.anpocs.com/index.php/papers-40-encontro-2/gt-30/gt08-26/10660-olegado-de-2013-coletivos-de-ativistas-e-a-agenda-politica-brasileira/file

PEREZ, Olívia; SOUZA, Bruno (2017), "Velhos, novos ou novíssimos movimentos sociais? As pautas e práticas dos coletivos", in $41^{\circ}$ Encontro Anual da ANPOCS, GT 11, Caxambu, MG [Consult. 10-05-2020]. Disponível em http://anpocs.com/index.php/encontros/papers/41-encontroanual-da-anpocs/gt-30/gt11-15/10696-velhos-novos-ou-novissimos-movimentos-sociais-as-pautase-praticas-dos-coletivos

PEREZ, Olívia (2017), "Surgimento e atuação dos coletivos que discutem clivagens sociais". II Encontro Internacional Participação, Democracia e Políticas Públicas, UFES, Vitória, ES [Consult. 10-05-2020]. Disponível em

https://www.researchgate.net/publication/318099286_Surgimento_e_atuacao_dos_Coletivos_que_ discutem_clivagens_sociais

. (2019), "Relações entre coletivos com as Jornadas de Junho". Opinião Pública, Campinas, v. 25, n. 3, pp.577-596 [Consult. 10-05-2020]. Disponível em https://doi.org/10.1590/180701912019253577

PINTO, Celi R. J. (2012), "Movimentos Sociais 2011: estamos frente a uma nova forma de fazer política?", in B. Bringel; M. G. Gohn (Orgs.). Movimentos sociais na era global. Petrópolis, Editora Vozes, pp. 129-145.

RIBEIRO, Letícia; O’DWYER, Brena; HEILBORN, Maria (2018), "Dilemas do feminismo e a possibilidade de radicalização da democracia em meio às diferenças: o caso da marcha das vadias no Rio de Janeiro". Civitas - Revista de Ciências Sociais, v. 18, n. 1, pp. 83-99 [Consult. 10-052020]. Disponível em https://doi.org/10.15448/1984-7289.2018.1.27560

ROLNIK, Raquel (2013), “As vozes das ruas: as revoltas de junho e suas interpretações". In: Cidades Rebeldes: Passe livre e as manifestações que tomaram as ruas do Brasil, São Paulo, Carta Maior, Boitempo, pp. 7-12. 
SANCHO, Guiomar (2018), "Multidões conectadas e movimentos sociais: dos zapatistas e do hacktivismo à tomada das ruas e das redes", in: B. Cardoso; B. Bruno; F. Melgaço; L. Guilhon (Orgs.). Tecnopolíticas da vigilância: Perspectivas da margem. São Paulo, Boitempo, pp. 355-376.

SANTOS, Francine (2017), Resistências ativas e resistências reativas: um estudo sobre os coletivos que contestam as práticas violentas da polícia no Estado de São Paulo. Dissertação (Mestrado em Ciências Humanas e Sociais). PCHS, UFABC, São Bernardo do Campo. 149p.

SCHOLZ, Trebor (2010), "Infrastructure: Its Transformations and Effect on Digital Activism". In: M. C. Joyce (Org.). Digital Activism Decoded: The new mechanics of change, New York, Idebate Press, pp. 17-32.

SILVEIRA, Sérgio Amadeu; BRAGA, Sérgio; PENTEADO, Cláudio (2014), Cultura, Política e Ativismo nas Redes Digitais. São Paulo, Fundação Perseu Abramo.

TEIXEIRA, Ana; ZANINI, Débora; MENESES, Larissa (2017), “O fazer político nas mídias sociais: aproximações teóricas sobre ação coletiva em rede", in $41^{\circ}$ Encontro Anual da ANPOCS, GT 2, Caxambu, MG [Consult. 10-05-2020]. Disponível em https://www.anpocs.com/index.php/papers40-encontro-2/gt-30/gt02-25/11055-o-fazer-politico-nas-midias-sociais-aproximacoes-teoricassobre-acao-coletiva-em-rede-1/file 


\begin{abstract}
In the last decade, the self-styled "collective" groups, become visible in the scenario of political mobilizations and academic researches, bringing analytical challenges to the field of collective action, considering the complexity and plurality found on them. The main goal of this article is to reflect on the building of horizontal and collaborative forms of organization of collectives and their use of digital Information and Communications Technology (ICT), as well the relationship between these both aspects. The organizational practices and political performance of these groups are analyzed from the result of research realized with five collectivist groups from São Paulo city, related to a historical resumption of the 2010 cycle of protests, presenting a historical and procedural perspective of collective struggles. The debate about the relationship between horizontality, TDIC, and forms of leadership seeks to analyze the building of horizontal and collaborative practices, indicating convergences between the experiences of the cycle and the practices of collectives, and contributes to the reflection on the contemporary scenario of collective action.
\end{abstract}

Key words: Protest cycle; collective; horizontality; digital information and communication technologies.

\title{
Resumen
}

En la última década, los grupos que se autodenominan "colectivos" han ganado visibilidad en el contexto de las movilizaciones políticas y la investigación académica, trayendo desafíos analíticos al campo de la acción colectiva, dada la complejidad y pluralidad que presentan. El objetivo del artículo es reflexionar sobre la construcción de formas horizontales y colaborativas de organización de los colectivos y el uso que hacen de las tecnologías de información y comunicación digital, así como la relación entre estos aspectos. Las prácticas organizativas y políticas de estos grupos se analizan a partir del material resultante de la investigación realizada con cinco colectivos que operan en la ciudad de São Paulo en diálogo con el panorama histórico del ciclo de protestas de los años 2010, presentando una perspectiva histórica y procesual de las luchas colectivas. El debate sobre la relación entre la horizontalidad, las TIC y las formas de liderazgo busca analizar la construcción de prácticas horizontales y colaborativas, señalando las convergencias entre las experiencias del ciclo y las prácticas de los colectivos, y contribuye a la reflexión sobre el escenario contemporáneo de la acción colectiva.

Palabras clave: Ciclo de protestas; colectivo; horizontalidad; tecnologías digitales de la información y la comunicación. 